DOI: 10.1515/adms-2017-0013

\title{
A. Kausar
}

Nanoscience and Technology Department, National Centre For Physics, Quaid-i-Azam

University Campus, Islamabad, Pakistan

asheesgreat@yahoo.com

\section{POLYAMIDE 1010/POLYTHIOAMIDE BLEND REINFORCED WITH GRAPHENE NANOPLATELET FOR AUTOMOTIVE PART APPLICATION}

\begin{abstract}
Novel polythioamide (PTA) was prepared and blended with polyamide 1010 (PA1010). Based on morphology, molecular weight, polydispersity index, thermal, and shear stress behavior, PA1010/PTA (90:10) blend was opted as matrix for graphene nanoplatelet (GNP) reinforcement. Inclusion of functional GNP resulted in crumpled gyroid morphology. $\mathrm{T}_{0}\left(502^{\circ} \mathrm{C}\right)$ of PA1010/PTA/GNP was increased by $145^{\circ} \mathrm{C}$ than unfilled blend $\left(357^{\circ} \mathrm{C}\right)$. Limiting oxygen index measurement indicated better non-flammability of PA1010/PTA/GNP1-3 nanocomposites (53-55\%) relative to PA1010/PTA1-3 (41-48\%). PA1010/PTA/GNP1-3 also attained V-0 rating in UL94. Furthermore, PA1010/PTA/GNP3 nanocomposite revealed optimum tensile strength (40 MPa), impact strength (1.9 MPa), and flexural modulus (1373 $\mathrm{MPa}$ ) to manufacture automotive part.
\end{abstract}

Keywords: Polyamide 1010, graphene nanoplatelet, automotive

\section{INTRODUTION}

Polyamide is an important class of engineering polymers [1, 2]. Polyamides-based nanocomposites have attracted much attention due to outstanding properties such as high modulus, high heat distortion temperature, good barrier properties, and fireproof characteristics [3-5]. Nylon 1010 or Polyamide 1010 (PA1010) is one of the significant commercially produced engineering polyamide [6]. It possesses high strength, elasticity, toughness, and abrasion resistance [7-9]. However, there are some inherent drawbacks of nylons due to polar amide bonds such as moisture absorption. It is possible to overcome these drawbacks through the preparation of PAA1010 blends and nanocomposites [10,11]. PA1010 nanocomposites have been prepared with high modulus and onset temperature of decomposition compared with neat nylon 1010. In blends form, most polymers are immiscible from the thermodynamic point of view, so compatibilization is essential. To enhance the compatibility, various techniques have been applied successfully such as the use of suitable processing technique and compatiblizing agents. Rheological study of polyamide blends has shown that the dynamic viscosity at low shear rate 
frequencies was very sensitive to the nature of blend matrix [12]. Similarly molecular weight variations in blends may provide important knowledge on polyamide blend processability. Despite the commercial importance of compatibilized polyamide blend systems, more research is needed in this field. In this regard filled or reinforced polyamide blends need to be prepared with enhanced properties. Graphene nanoplatelet (GNP) is a few layer graphene $[13,14]$. It is an attractive nanofiller for polymer matrices. Graphene nanoplatelet possesses excellent balance of physical properties and cost. Polymeric nanocomposite with graphene platelet reveal high modulus and strength, fine barrier properties, and excellent electrical and thermal properties [15, 16]. Consequently, GNP is considered as an efficient reinforcing nanofiller compared with carbon nanotube and other carbon nanofillers in polymers [17, 18]. Functionalization of GNP has been used as an effective method to improve particle dispersion and material properties [19, 20]. In present work, blend of PA11010 with a novel polythioamide (PTA) have been prepared. Afterward, the selected PA1010/PTA blend composition was reinforced with functional GNP nanofiller. Property variation in different blend compositions and effect of nanofiller on reinforced system have been analyzed using rheology, molecular weight, thermal, flammability and automotive studied. To the best of knowledge, these PA1010 blends and nanocomposites have been prepared for the first time and employed for automotive part application.

\section{EXPERIMENTAL}

\section{Chemicals}

PA1010 was obtained from Shanghai Celluloid Factory (China). 2-Aminoethanethiol (98\%), 2,6-pyridine-dicarbonyl dichloride (97\%), dimethyl formamide (DMF, 99\%), N-methyl2-pyrrolidone (NMP, 98\%), and triethylamine (99.5\%) were obtained from Aldrich.

\section{Measurements}

Fourier transform infrared spectroscopy (FTIR) Spectrometer FTSW 300 MX (BIO-RAD) was used to scan the spectra of samples in the range of $400-4000 \mathrm{~cm}^{-1}$. Gel permeation chromatography (GPC) was used to evaluate the number-average molecular weight $\left(\mathrm{M}_{\mathrm{n}}\right)$, weightaverage molecular weight $\left(\mathrm{M}_{\mathrm{w}}\right)$, and polydispersity index (PDI). DMF was used as an eluent. The micrographs were obtained by Scanning Electron Microscope S-4700 (Japan Hitachi Co. Ltd.). Rheological measurements were performed using a Parr Physica UDS 200 mechanical rheometer (Stuttgart, Germany) at room temperature. An angle of $2^{\circ}$ was used for steady state and frequency measurements. Cone and plate geometry was used with radius of $50 \mathrm{~mm}$ and gap size of $0.05 \mathrm{~mm}$. Thermal stability was determined by NETZSCH thermo gravimetric analyzer (TGA), model no. TG $209 \mathrm{~F} 3$ (California, USA), using $5 \mathrm{mg}$ of sample in $\mathrm{Al}_{2} \mathrm{O}_{3}$ crucible. The temperature range was taken from 0 to $700^{\circ} \mathrm{C}$ at heating rate of $10{ }^{\circ} \mathrm{C} / \mathrm{min}$ under nitrogen atmosphere. Limiting oxygen index (LOI) measurements were performed on a Stanton Redcroft FTA flammability unit provided with an Oxygen Analyzer. UL-94 test was performed $(110 \times 10.1$ $\times 3 \mathrm{~mm}^{3}$ ) according to ASTM D635-77. Flexural properties were studied as per ASTM-D-790 with crosshead speed of $2 \mathrm{~mm} / \mathrm{min}$. Tensile properties were measured as per ASTM-D-638 using gauge of $50 \mathrm{~mm}$ and cross-head speed of $2 \mathrm{~mm} / \mathrm{min}$. For waist line molding, blend and composite 
samples were injection-molded using LGH-80D injection molding machine. The temperature used was $200{ }^{\circ} \mathrm{C}$ with injection speed of $120 \mathrm{MPa}$ and $80 \mathrm{~cm}^{3} / \mathrm{s}$.

Acid-functionalization of graphene nanoplatelet (GNP)

Prior to use, $1 \mathrm{~g}$ GNP was refluxed in a mixture of $\mathrm{H}_{2} \mathrm{SO}_{4}(8 \mathrm{M})$ and $\mathrm{HNO}_{3}(3 \mathrm{M})$ in ratio 3:1 for $6 \mathrm{~h}\left(70^{\circ} \mathrm{C}\right)$. After reflux, mixture was poured in $500 \mathrm{~mL}$ of deionized water and kept for $24 \mathrm{~h}$. The mixture was filtered and washed several times with deionized water to attain neutral $\mathrm{pH}$. After maintenance of $\mathrm{pH}$, acid functional GNP was dried in an oven at $100^{\circ} \mathrm{C}(3 \mathrm{~h})$ [20].

\section{Formation of polythioamide (PTA)}

In $200 \mathrm{~mL}$ round bottom flask equipped with nitrogen, 2-aminoethanethiol hydrochloride $(0.01 \mathrm{~mol})$ and $50 \mathrm{~mL}$ DMF were charged. The mixture was placed in an ice bath with constant stirring. $5 \mathrm{~mL}$ triethylamine was then added to the mixture via syringe. The mixture was stirred for $2 \mathrm{~h}$. Afterwards, 2,6-pyridinedicarbonyl dichloride $(0.01 \mathrm{~mol})$ was dissolved in $10 \mathrm{~mL}$ DMF and added drop wise to the reaction flask (Fig. 1). The mixture was precipitated in water and filtered to obtain the polyamide [21]. FTIR $\left(\mathrm{cm}^{-1}\right): 3339$ (N-H stretch), $1590(\mathrm{~N}-\mathrm{H}$ bend), 3015 (aromatic $\mathrm{C}-\mathrm{H}$ stretch), 1680 (amide $\mathrm{C}=\mathrm{O}$ stretch), 1414 (C-N stretch).

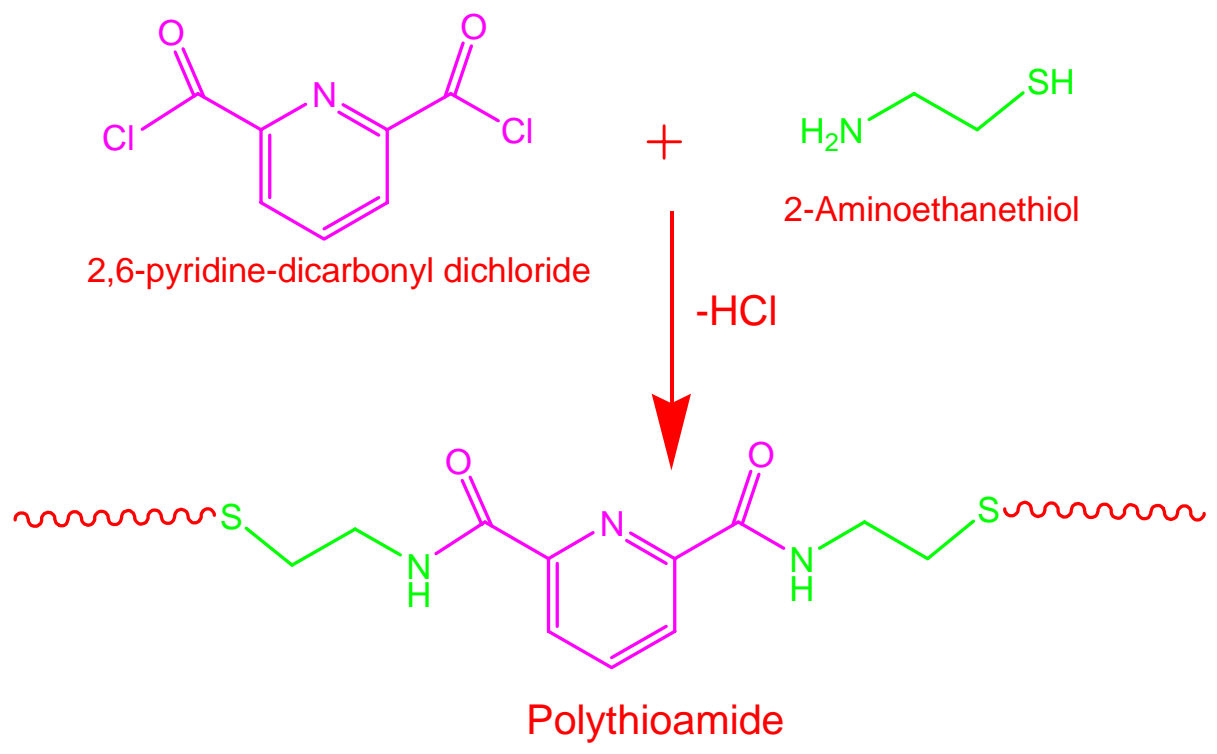

Fig. 1. Formation of polyamide

\section{Preparation of polyamide 1010/polythioamide blend (PA1010/PTA)}

First step was to dissolve $10 \mathrm{~g}$ PA1010 in $100 \mathrm{~mL}$ NMP. For the purpose, ingredients were added to a $200 \mathrm{~mL}$ pressure resistant glass autoclave. In nitrogen atmosphere, the mixture was heated up to $180^{\circ} \mathrm{C}$ for $5 \mathrm{~h}$ until the polymer was dissolved. PA1010/PTA blend was prepared in composition ratios of 10:90, 50:50, 20:80, and 90:10 by weight (Fig. 2). The blends were 
prepared using NMP as solvent at reflux temperature of $180{ }^{\circ} \mathrm{C}(2 \mathrm{~h})$. Finally, the blends films were cast by evaporating the solvent at $100{ }^{\circ} \mathrm{C}$ for $24 \mathrm{~h}$ [22]. FTIR $\left(\mathrm{cm}^{-1}\right): 3288(\mathrm{~N}-\mathrm{H}$ stretch), 1585 (N-H bend), 3009 (aromatic C-H stretch), 1677 (amide C=O stretch), 1410 (C-N stretch).

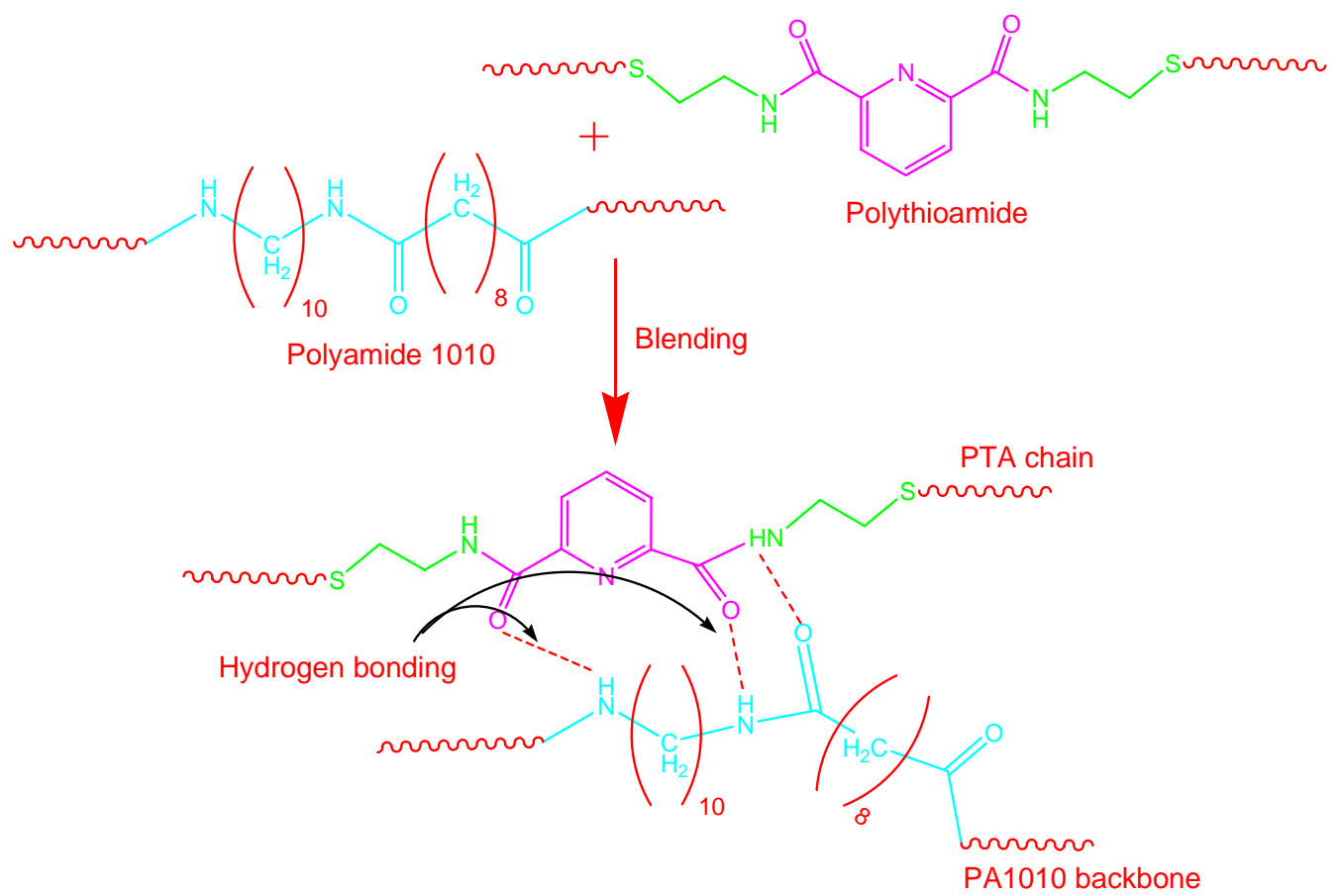

Fig. 2. Formation of polyamide1010/polythioamide blend

Formation of polyamide 1010/polythioamide and graphene nanoplatelet nanocomposite (PA1010/PTA/GNP)

PA1010/PTA 90:10 was opted to form the nanocomposite reinforced with graphene nanoplatelet. The PA1010/PTA/GNP nanocomposite with various GNP loading (0.01-0.03 wt.\%) were prepared using solution method (Fig. 3). Initially, PA1010/PTA blend was prepared using NMP as solvent (Section 2.5). After $2 \mathrm{~h}$ of reflux at $180{ }^{\circ} \mathrm{C}$, desired amount of GNP was added and the mixture was further refluxed for $2 \mathrm{~h}$. The nanocomposite films were cast by evaporating the solvent at $100^{\circ} \mathrm{C}$ for $24 \mathrm{~h}$ [23]. Table 1 shows the composition of the blends and nanocomposites prepared in this study. FTIR $\left(\mathrm{cm}^{-1}\right): 3499(\mathrm{O}-\mathrm{H}$ stretch), $3267(\mathrm{~N}-\mathrm{H}$ stretch), $1580(\mathrm{~N}-\mathrm{H}$ bend), 3001 (aromatic $\mathrm{C}-\mathrm{H}$ stretch), 1667 (amide $\mathrm{C}=\mathrm{O}$ stretch), 1410 (C-N stretch).

Table 1. Sample composition prepared in this study 


\begin{tabular}{lccc}
\hline \multirow{2}{*}{ Sample } & \multicolumn{2}{c}{ Composition } & GNP \\
\cline { 2 - 3 } & PA1010 & PTA & (wt. \%) \\
\hline PA1010/PTA 1 & 10 & 90 & - \\
PA1010/PTA 2 & 50 & 50 & - \\
PA1010/PTA 3 & 90 & 10 & - \\
PA1010/PTA/GNP 1 & 90 & 10 & 0.01 \\
PA1010/PTA/GNP 2 & 90 & 10 & 0.02 \\
PA1010/PTA/GNP 3 & 90 & 10 & 0.03 \\
\hline
\end{tabular}

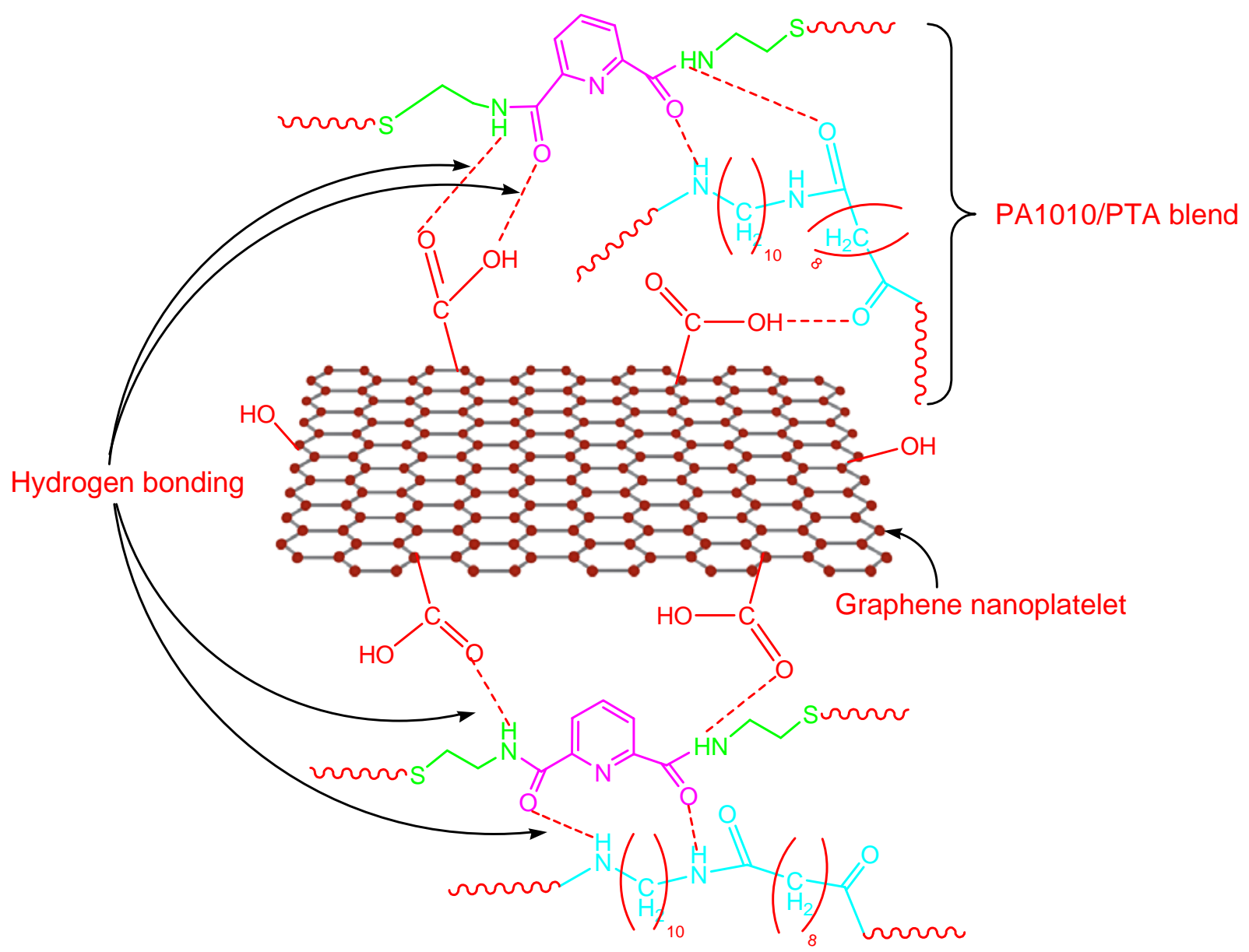

Fig. 3. Interaction in PA1010/PTA/GNP nanocomposite 


\section{Molecular weight, rheology, and structure studies}

Effect of blend composition as well as GNP loading on molecular weight of the prepared systems was investigated using GPC. The $\mathrm{M}_{\mathrm{n}}, \mathrm{M}_{\mathrm{w}}$, and polydispersity of the blends and nanocomposite are given in Table 2. With the increase in the PA1010 component in the blend series, molecular weight was found to increase from $63,000-67,000 \mathrm{~g} / \mathrm{mol}\left(\mathrm{M}_{\mathrm{w}}\right)$. The increase in the molecular weight was attributed to better polymer chain interaction in PA1010/PTA (90:10) blend as well as inherently high molecular weight of PA1010 component (90\%). Polydispersity index of PA1010/PTA 3 (1.9) was also higher than the PDI of PA1010/PTA 1 (1.5). The results also suggest that the PA1010/PTA 1 with 10:90 (PA1010/PTA) blend ratio was uncompatibilized relative to PA1010/PTA 3 with lower PTA content. Based on these results, PA1010/PTA 3 composition was opted to form nanocomposites, in this study. This observation offers evidence of interfacial capacity of PTA to homogenize a polymer blend, at minor phase concentration of $10 \mathrm{wt} . \%$. It is also interesting to compare the molecular weight results with the graphene nanoplatelet loaded PA1010/PTA. Generally, inclusion of nanofiller is expected to decrease the molecular weight of the polymers.

Table 2. Molecular weight studies of PA1010/PTA blends and nanocomposite

\begin{tabular}{lc|cc}
\hline \multicolumn{1}{c}{ Sample } & $\mathbf{M}_{\mathbf{n}}(\mathbf{g} / \mathbf{m o l})$ & $\left.\mathbf{M}_{\mathbf{w}} \mathbf{( g / m o l}\right)$ & PDI \\
\hline PTA & 9,000 & 18,000 & 2.0 \\
PA1010 & 33,000 & 70,000 & 2.0 \\
PA1010/PTA 1 & 42,000 & 63,000 & 1.5 \\
PA1010/PTA 2 & 40,625 & 65,000 & 1.6 \\
PA1010/PTA 3 & 35,263 & 67,000 & 1.9 \\
PA1010/PTA/GNP 1 & 35,555 & 64,000 & 1.8 \\
PA1010/PTA/GNP 2 & 35,000 & 63,000 & 1.8 \\
PA1010/PTA/GNP 3 & 33,333 & 60,000 & 1.8 \\
\hline
\end{tabular}

The PA1010/PTA/GNP 1 with 0.01 wt.\% nanofiller loading depicted decrease in $\mathrm{M}_{\mathrm{n}}$ and $\mathrm{M}_{\mathrm{w}}$ to 35,555 and 64,000 $\mathrm{g} / \mathrm{mol}$ respectively relative to the unfilled blend. In the case of $0.02 \mathrm{wt}$. $\%$ nanofiller addition (PA1010/PTA/GNP 2), the molecular weight values were further decreased to 35,000 and $63,000 \mathrm{gmol}^{-1}$, respectively. Correspondingly, additional decrease was observed with 0.03 wt.\% GNP loading and $\mathrm{M}_{\mathrm{n}}=33,333 \mathrm{gmol}^{-1}$ and $\mathrm{M}_{\mathrm{w}}=60,000 \mathrm{gmol}^{-1}$ were obtained. Among these samples, highest declining effect on molecular weight was observed with $0.03 \mathrm{wt} . \%$ NP addition. PDI of the blends and nanocomposites showed same trend as molecular weight properties. It seems that the interaction between blend chains and GNP nanoparticle was strengthened with the increasing nanofiller loading. The reinforcement effect, thus, tends to decrease the polymer chain packing. Owing to well-developed interactions between polymer backbone and nanofiller, the chain scission phenomenon was evident, so decreasing the 
molecular weight of the nanocomposite [24]. Although, the $\mathrm{M}_{\mathrm{n}}, \mathrm{M}_{\mathrm{w}}$, and PDI values of nanocomposites were quite high to symbolize a reasonable molecular weight. Interaction between the blend components was also evident from the lowering in the amide group $\mathrm{N}-\mathrm{H}$ stretching and bending vibrations and carbonyl $\mathrm{C}=\mathrm{O}$ group stretching vibration. FTIR peaks for amide group were further shifted to lower frequency region in the case of nanocomposite due to physical interaction between the blend components and nanofiller (Section 2.4-2.6).

For rheological measurement, the shear rates range from $10^{-3}$ to $10^{3} \mathrm{~s}^{-1}$. Shear stress of PA1010/PTA 1 and PA1010/PTA 2 blends decreased with increasing PTA polymer concentrations. This observation suggests that the rheology was driven by the PTA component in the blend. The maximum shear stress value in blends was observed for PA1010/PTA 3 with higher PA1010 content. However, the values were higher than the filled blends. Typical shear stress-shear rate data for the PA1010/PTA blend and PA1010/PTA/GNP nanocomposite of different compositions are presented in Fig. 4. The yield stress was found to decrease with GNP content in the concentration range tested in this study. The rheology of the blend at high GNP content has low shear stress, suggesting that the property is governed by the dispersed phase. The results suggested that the blends were more viscous than the matrix. Moreover, PA1010/PTA 3 with low GNP loading was more viscous than other nanocomposites prepared, however less viscous than the blends. Yield stress values obtained were found comparable to the literature reported on polyamide blends [25].

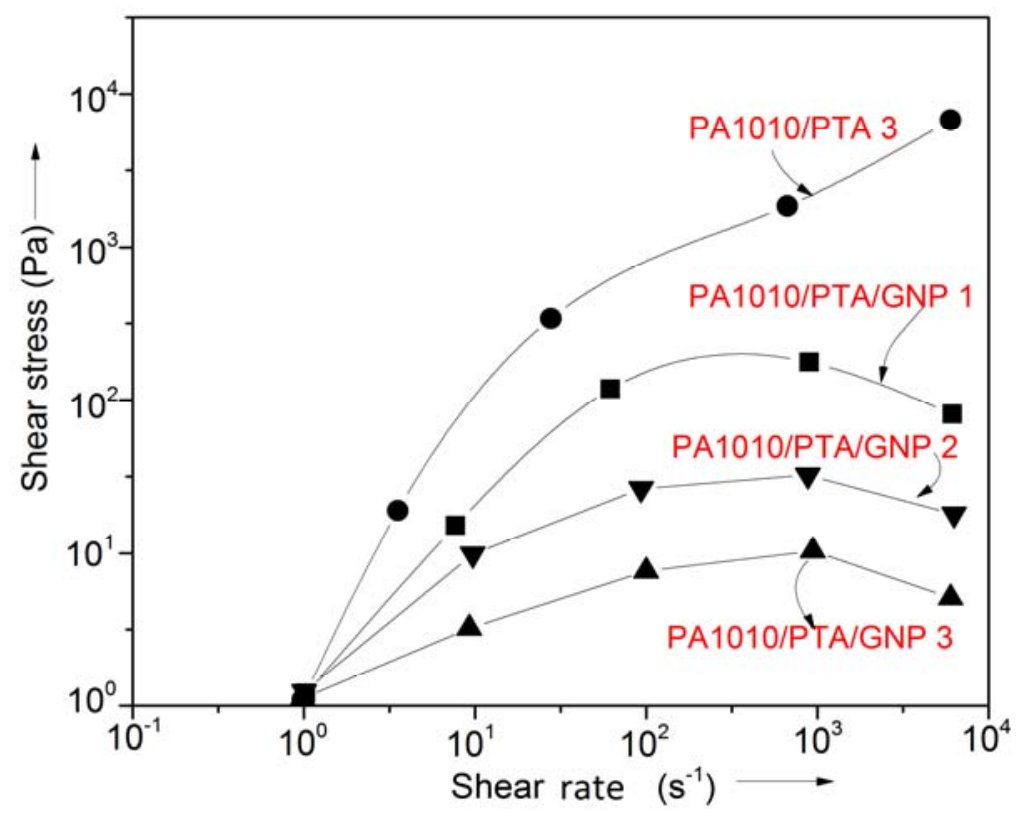

Fig. 4. Shear stress as a function of the shear rate for samples

\section{Morphology study}

Fig. 5A-C shows the unfilled blend morphology. In the case of PA1010/PTA 1 with 10:90 blend ratio, the polyamide 1010 matrix appeared as bigger particles in the polythioamide phase (Fig. 5A). The PA1010 particles seem to have large diameter and nearly globular shape. Moreover, the interfacial boundaries between nylon 1010 and PTA matrix were not distinct. 


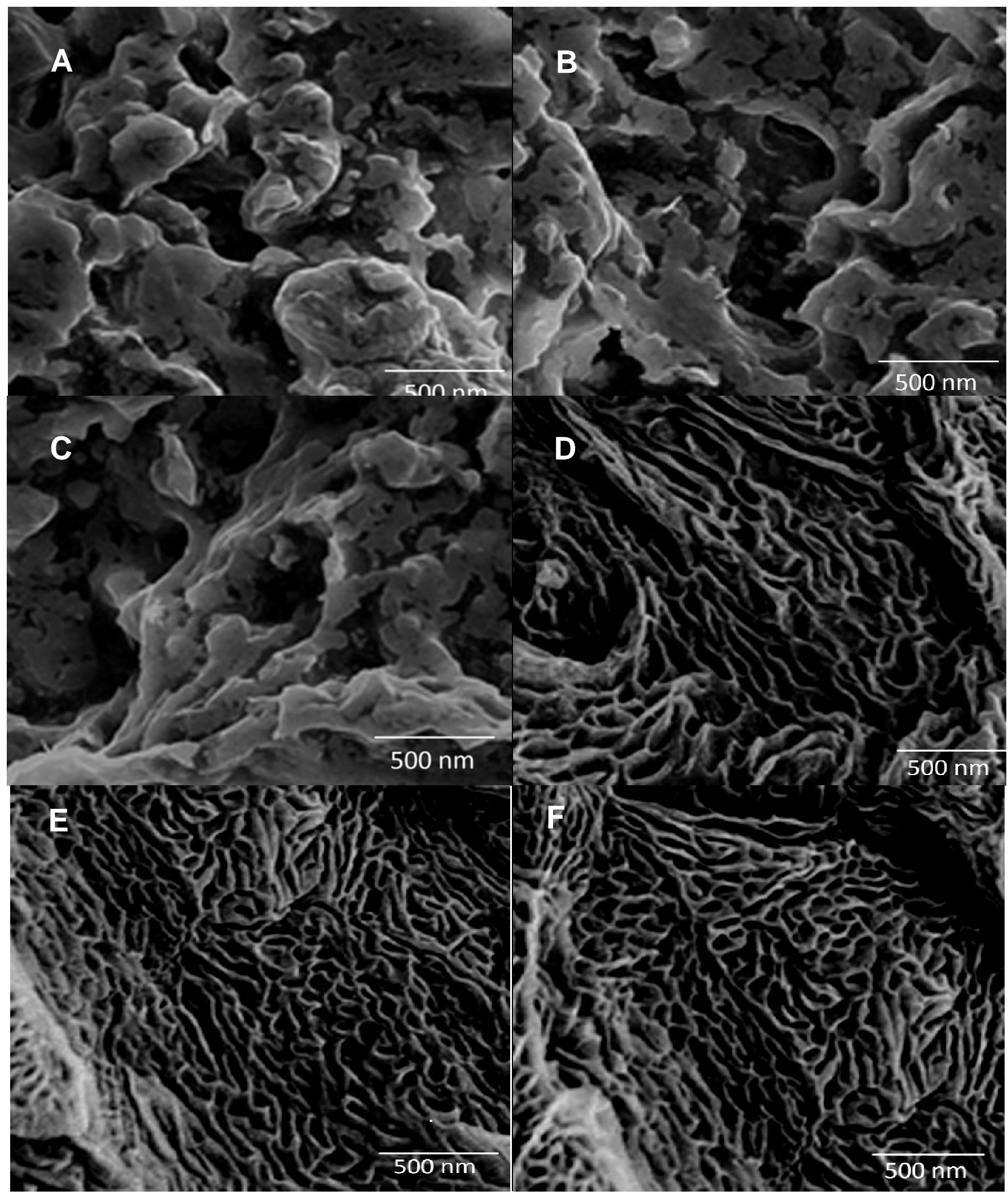

Fig. 5. FESEM images of (A) PA1010/PTA 1; (B) PA1010/PTA 2; (C) PA1010/PTA 3; (D) PA1010/PTA/GNP 1; (E) PA1010/PTA/GNP 2; and (F) PA1010/PTA/GNP 3 
The increase in polyamide content led to considerable decrease in the size of dispersed aggregated particles. Fig. 5C shows the formation of compatible blend (PA1010/PTA 3) relative to the PA1010/PTA 1. The results implied that the 10\% PTA developed fine interaction and dispersion in the PA1010 matrix (90\%). The addition of graphene nanoplatelet to the polymer molecules caused significant changes in the morphology of PA1010/PTA blends (Fig. 5D-F). The blend attained some specific crumbling gyroid type of morphology. The pattern was more finely textured in the case of PA1010/PTA/GNP 3 nanocomposite with higher graphene nanoplatelet loading. However, the graphene nanoplatelet flakes were not visible at the fractured surface. The observed change in the morphology may be attributed directly to the physical contact between the blend components and GNP. Moreover, refinement of the microstructure implies the formation of compatibilized system with improved interfacial adhesion stabilizing the nanofiller dispersion [26].

\section{Thermal stability and flammability measurement}

Table 3 shows the thermal analysis data of neat polythioamide, blends, and nanocomposite. The data include the onset degradation temperature $\left(\mathrm{T}_{0}\right)$, the temperature at which $10 \%$ weight loss occurs $\left(\mathrm{T}_{10}\right)$, and maximum weight loss temperature $\left(\mathrm{T}_{\max }\right)$. The $\mathrm{T}_{0}$ of polythioamide was $333^{\circ} \mathrm{C}, \mathrm{T}_{10}$ was $388^{\circ} \mathrm{C}$, and $\mathrm{T}_{\max }$ was around $399^{\circ} \mathrm{C}$ (Fig. 6).

Table 3. Thermal analyses data of polyamide and nanocomposite

\begin{tabular}{lccccc}
\hline \multicolumn{1}{c}{ Composition } & $\begin{array}{c}\mathbf{T}_{\mathbf{0}} \\
\left({ }^{\circ} \mathbf{C}\right)\end{array}$ & $\begin{array}{c}\mathbf{T}_{\mathbf{1 0}} \\
\left({ }^{\circ} \mathbf{C}\right)\end{array}$ & $\begin{array}{c}\mathbf{T}_{\mathbf{m a x}} \\
\left({ }^{\circ} \mathbf{C}\right)\end{array}$ & $\begin{array}{c}\text { LOI } \\
(\mathbf{\%})\end{array}$ & $\mathbf{U L ~ 9 4}$ \\
\hline PTA & 333 & 388 & 399 & 24 & $\mathrm{~V}-0$ \\
PA1010/PTA 1 & 340 & 410 & 450 & 41 & $\mathrm{~V}-1$ \\
PA1010/PTA 2 & 356 & 421 & 454 & 45 & $\mathrm{~V}-1$ \\
PA1010/PTA 3 & 357 & 422 & 455 & 48 & $\mathrm{~V}-1$ \\
PA1010/PTA/GNP 1 & 479 & 532 & 567 & 53 & $\mathrm{~V}-0$ \\
PA1010/PTA/GNP 2 & 492 & 543 & 577 & 54 & $\mathrm{~V}-0$ \\
PA1010/PTA/GNP 3 & 502 & 555 & 588 & 55 & $\mathrm{~V}-0$ \\
\hline
\end{tabular}

In the blend system PA1010/PTA 1 showed onset temperature of degradation at $340^{\circ} \mathrm{C}$, while $\mathrm{T}_{\max }$ was increased up to $450^{\circ} \mathrm{C}$. Thermal stability of PA1010/PTA 3 was slightly increased with $\mathrm{T}_{0}, \mathrm{~T}_{10}$, and $\mathrm{T}_{\max }$ of 357,422 , and $455^{\circ} \mathrm{C}$, respectively. Hence, the thermal stability of blends was found to increase relative to the neat PTA. Formation of nanocomposites significantly enhanced the thermal properties of the selected PA1010/PTA blend. The $\mathrm{T}_{0}$ of PA1010/PTA/GNP 1 nanocomposite was $479^{\circ} \mathrm{C}, \mathrm{T}_{10}$ was $532^{\circ} \mathrm{C}$, and $\mathrm{T}_{\max }$ was around $567^{\circ} \mathrm{C}$. For PA1010/PTA/GNP 2 nanocomposite, the onset degradation occurred at higher temperature of $492^{\circ} \mathrm{C}$, while $\mathrm{T}_{\max }$ was increased to $577^{\circ} \mathrm{C}$. The thermal stability of $0.3 \mathrm{wt} . \%$ nanocomposite was found considerably higher than that of neat polythioamide and other nanocomposites. Therefore, 
the higher values for $\mathrm{T}_{0}, \mathrm{~T}_{10}$ and $\mathrm{T}_{\max }$ were observed at 502,555 , and $588^{\circ} \mathrm{C}$, respectively. The comparison between the TGA results of nanocomposites and PA1010/PTA 3 blend showed that the thermal decomposition of PA1010/PTA/GNP 3 nanocomposites was initiated $145^{\circ} \mathrm{C}$ above the nitial thermal decomposition of the blend. Similarly, there was marked increase in the $\mathrm{T}_{10}$ and $\mathrm{T}_{\max }$ of the nanocomposites.

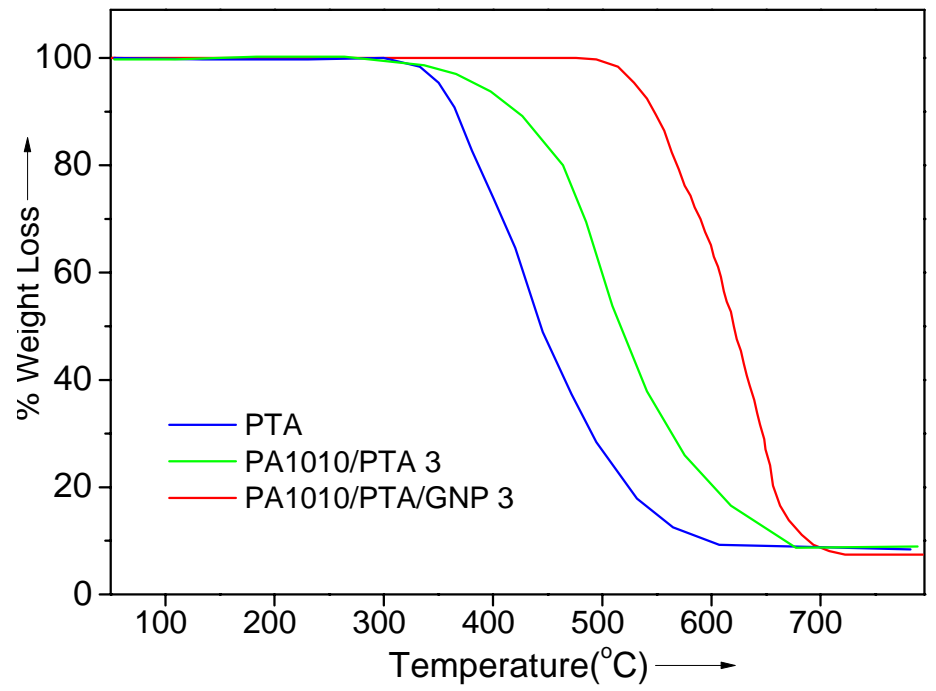

Fig. 6. TGA curves of PTA, PA1010/PTA 3, and PA1010/PTA/GNP 3 nanocomposite at 10 oC/min (N2)

To evaluate the flame retardancy, limiting Oxygen Index (LOI) values were recorded on a Stanton Redcroft flame meter using a modified method. LOI value of neat polythioamide was found to be 24. The LOI value of blends were in the range of 41-48. However, in the case of PA1010/PTA/GNP 1-3 nanocomposites, the flame resistance was increased from 53 to 55 . There appeared to be a correlation between the limiting oxygen index and the nanofiller loading. The introduction of GNP noticeably increased the flame retardancy of the nanocomposite, while sustaining their thermal stability [27]. Thus, the influence GNP was observed on nanocomposites during the flame retarding test. According to UL94 test, PA1010/PTA/GNP 1-3 nanocomposites also attained V-0 rating.

\section{Design of automotive part}

For real application of polyamide and graphene nanoplatelet-based nanocomposite for automotive parts, waist line molding has been prepared using PA1010/PTA/GNP 3. Fig. 7 shows the image of injection-molded waist line molding prepared. The PA1010/PTA (90:10) with 0.03 wt.\% GNP was melt compounded to prepare the automotive part. 


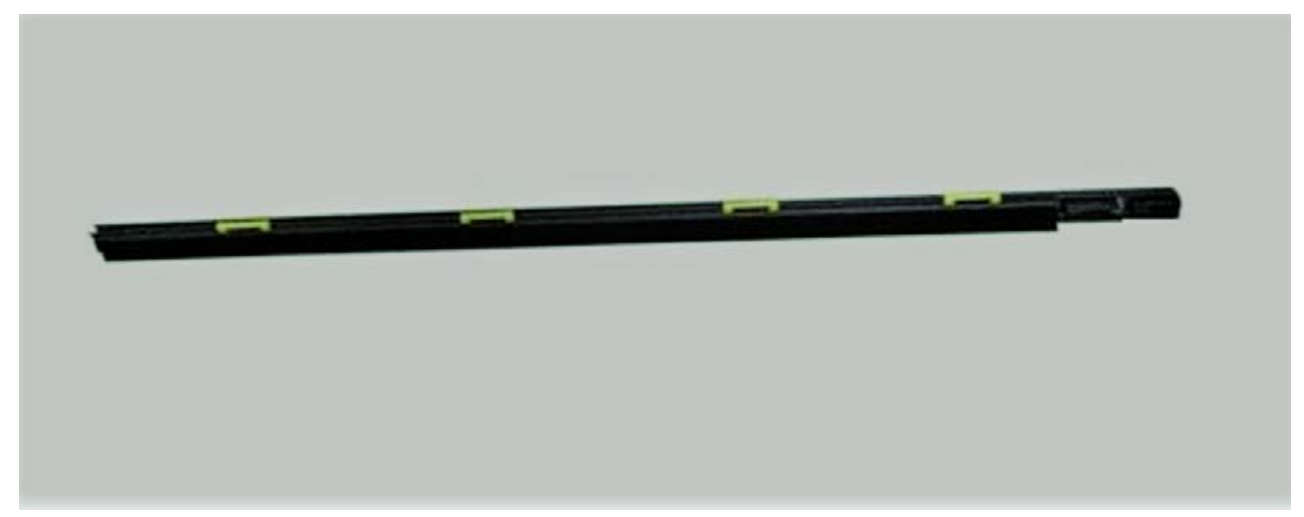

Fig. 7. Photograph of injection-molded waist line molding prepared by using PA1010/PTA/GNP 3 nanocomposite

Table 4 shows the mechanical properties of PA1010/PTA blend as well as PA1010/PTA/GNP 1 and PA1010/PTA/GNP 3 nanocomposite. Compared with the blend, PA1010/PTA/GNP 3 nanocomposite showed improvement in tensile strength (40 $\mathrm{MPa})$ and flexural modulus (1373 $\mathrm{MPa})$ as well as low \% elongation. These are key parameters for dimensional stability of material to manufacture large vehicle parts. Impact property of the nanocomposite was also higher than that of the corresponding blend. Using very low GNP content, remarkable mechanical properties have been achieved for PA1010/PTA/GNP 3 nanocomposite. The tensile and flexural results were also found better than the reported composites used in automotive parts [28, 29].

Table 4. Mechanical properties of compounded waist line molding using PA1010/PTA/GNP nanocomposite

\begin{tabular}{|c|c|c|c|c|c|c|c|}
\hline \multirow{2}{*}{ Sample } & \multicolumn{2}{|c|}{ Composition } & \multirow{2}{*}{$\begin{array}{c}\text { GNP } \\
\text { (wt.\%) }\end{array}$} & \multirow{2}{*}{$\begin{array}{c}\text { Tensile } \\
\text { strength } \\
\text { (MPa) }\end{array}$} & \multirow{2}{*}{$\begin{array}{c}\text { Elongation } \\
(\%)\end{array}$} & \multirow{2}{*}{$\begin{array}{c}\text { Flexural } \\
\text { strength } \\
\text { (MPa) }\end{array}$} & \multirow{2}{*}{$\begin{array}{l}\text { Impact } \\
\text { strength } \\
\text { (MPa) }\end{array}$} \\
\hline & PA1010 & PTA & & & & & \\
\hline PA1010/PTA 3 & 90 & 10 & 0 & 15 & 20 & 1166 & 1.1 \\
\hline PA1010/PTA/GNP & 90 & 10 & 0.01 & 20 & 12 & 1221 & 1.2 \\
\hline PA1010/PTA/GNP 3 & 90 & 10 & 0.03 & 40 & 10 & 1373 & 1.9 \\
\hline
\end{tabular}

CONCLUSIONS

An aromatic polythioamide was synthesized and used as a blend component with nylon 1010 . The PA1010/PTA (90:10) blend with optimum molecular weight and rheological properties was opted as matrix material to form nanocomposite. GNP was found as remarkable nanofiller affecting the morphological, mechanical, and automotive properties. The results also demonstrated that the incorporation of GNP nanoparticle enhanced the thermal and flammability properties of processable blends and nanocomposites. Novel nylon 1010-based materials, thus, can be considered as a candidate for the preparation of high-temperature resistant automotive materials. For automotive parts application, PA1010/PTA/GNP 3 nanocomposite with suitable tensile, flexural, and impact properties was injection-molded using the relevant technique. The automotive waist line molding was successfully designed. Future research on the effect of higher GNP loading on tensile, flexural, and impact properties of PA1010-based materials will introduce a new class of nano-particulate filled polyamide nanocomposite for automotive applications. 
Novel nylon 1010 nanocomposite may also offer advantages of rheology and processing properties as compared to the polymeric composites currently used in automotive parts fabrication.

\section{REFERENCE}

1. Jia Y., He H., Peng X., Meng S., Chen J., Geng, Y., Preparation of a new filament based on polyamide-6 for three-dimensional printing. Polym. Engineer. Sci. (2017) DOI,10.1002/pen.24515.

2. Kausar A., Polycarbonate/Polypropylene-Graft-Maleic Anhydride and Nano-Zeolite-Based Nanocomposite Membrane, Mechanical and Gas Separation Performance. Adv. Mater. Sci. 16 (2016)17-28.

3. Kausar A., Ullah W., Muhammad B., Siddiq, M., Novel mechanically stable, heat resistant and nonflammable functionalized polystyrene/expanded graphite nanocomposites, Adv. Mater. Sci. 14 (2014) 61-74.

4. Kausar A., Mechanical, thermal, and electrical properties of epoxy matrix composites reinforced with polyamide-grafted-MWCNT/poly (azo-pyridine-benzophenone-imide)/polyaniline nanofibers. Int. J. Polym. Mater. Polym. Biomater. 63 (2014) 831-839.

5. Katunin A., Krukiewicz K., Herega A., Catalanotti, G., Concept of a conducting composite material for lightning strike protection. Adv. Mater. Sci. 16 (2016) 32-46.

6. Budzik M., Pilawka R., Imielińska K., Jumel J., Shanahan M., Fracture of Aluminium Joints Bonded with Epoxy Adhesive Reinforced by MMT Nanoparticles. Adv. Mater. Sci. 9 (2009) 4-11.

7. Zhang S.L., Wang G.B., Jiang Z.H., Wang D., Ma R.T., Wu Z.W., Impact properties, phase structure, compatibility, and fracture morphology of polyamide-1010/thermoplastic poly (ester urethane) elastomer blends. J. Polym. Sci. B, Polym. Phys. 43 (2005) 1177-1185.

8. Kausar A., Effect of nanofiller dispersion on morphology, mechanical and conducting properties of electroactive shape memory Poly (urethane-urea)/functional nanodiamond composite, Adv. Mater. Sci. 15 (2015) 14-28.

9. Kausar A., Mechanical and Thermal Properties of Polyamide 1010 Composites Filled with Nanodiamond/Graphitized Carbon Black Nanoparticles. Am. J. Polym. Sci. Engineer. 3 (2015) 161171.

10. Lu Z., Wu A., Ou X., Zhang S., Niu J., Ji S., Ling Y., Enhanced anti-aging and mechanical properties of polyamide 1010 by sol-hydrothermal synthetic titanium dioxide-coated kaolinite addition. J. Alloys Comp. 693 (2017) 381-388.

11. Li B., Zhang L., ESR approach to free radicals trapped in irradiated polyamide-1010. Rad. Phys. Chem. 49 (1997) 395-397.

12. Sangroniz L., Palacios JK., Fernández M., Eguiazabal JI., Santamaria A., Müller AJ., Linear and nonlinear rheological behavior of polypropylene/polyamide blends modified with a compatibilizer agent and nanosilica and its relationship with the morphology. Eur. Polym. J. 83 (2016) 10-21.

13. Kausar A., Ur Rahman A., Functional Graphene Nanoplatelet Reinforced Epoxy Resin and Polystyrene-based Block Copolymer Nanocomposite. Full. Nanotub. Carb. Nanostruct. 24 (2016) 235-242. 
14. Kulkarni, H., Tambe, P., Joshi, G., 2017. High concentration exfoliation of graphene in ethyl alcohol using block copolymer surfactant and its influence on properties of epoxy Nanocomposites. Full. Nanotub. Carb. Nanostruct. (2016) DOI,10.1080/1536383X.2017.1283616.

15. Wang F., Drzal LT., Qin Y., Huang Z., Enhancement of fracture toughness, mechanical and thermal properties of rubber/epoxy composites by incorporation of graphene nanoplatelets. Compos. Part A, Appl. Sci. Manufact. 87 (2016) 10-22.

16. Wang F., Drzal L.T., Qin Y., Huang Z., Mechanical properties and thermal conductivity of graphene nanoplatelet/epoxy composites. J. Mater. Sci, 50 (2015) 1082-1093.

17. Ma PC., Siddiqui NA., Marom G., Kim JK., Dispersion and functionalization of carbon nanotubes for polymer-based nanocomposites, a review. Compos. Part A, Appl. Sci. Manufact, 41 (2010) 13451367.

18. Cui L.J., Wang YB., Xiu W.J., Wang W.Y., Xu LH., Xu X.B., Meng Y., Li LY., Gao J., Chen LT., Geng HZ., Effect of functionalization of multi-walled carbon nanotube on the curing behavior and mechanical property of multi-walled carbon nanotube/epoxy composites. Mater. Des. 49 (2013) 279284.

19. Anwar Z., Kausar A., Khan LA., Muhammad, B., Modified graphene nanoplatelet and epoxy/block copolymer-based nanocomposite, physical characteristic and EMI shielding studies. Nanocomposites, 2 (2016) 141-151.

20. Paszkiewicz S., Szymczyk A., Livanov K., Wagner H.D., Roslaniec, Z., 2015. Enhanced thermal and mechanical properties of poly (trimethylene terephthalate-block-poly (tetramethylene oxide) segmented copolymer based hybrid nanocomposites prepared by in situ polymerization via synergy effect between SWCNTs and graphene nanoplatelets. Express Polym. Lett, 9 (2015) 509-524.

21. Itsuno S., Takahashi, S., Inside Cover, Synthesis of Chiral Polyamides Containing an (R, R)-1,2Diphenylethylenediamine Monosulfonamide Structure and Their Application to Asymmetric Transfer Hydrogenation Catalysis (ChemCatChem 3/2017). ChemCatChem, 9 (2017) 375-375.

22. Nishitani Y., Mukaida J., Yamanaka T., Kajiyama T., Kitano T., In Holzer CH, Payer M, editors. AIP Conference Proceedings, AIP Publishing, 1779 (2016) 060004.

23. Yan D., Zhang H.B., Jia Y., Hu J., Qi X.Y., Zhang Z., Yu, Z.Z., Improved electrical conductivity of polyamide 12/graphene nanocomposites with maleated polyethylene-octene rubber prepared by melt compounding. ACS Appl. Mater. Interface. 4 (2012) 4740-4745.

24. Yousef S., Visco A., Galtieri G., Nocita D., Espro C., Wear behaviour of UHMWPE reinforced by carbon nanofiller and paraffin oil for joint replacement. Mater. Sci. Engineer. C. 73 (2017) 234-244.

25. Kim J.Y., Song J.Y., Lee J.E., Park S.K., Rheological properties and microstructures of Carbopol gel network system. Colloid Polym. Sci. 281 (2003) 614-623.

26. Beck Tan N.C., Tai S.K,. Bribert R.M., Morphology control and interfacial reinforcement in reactive polystyrene/amorphous polyamide blends. Polymer. 37 (1996) 3509-3519.

27. Wang J.Q., Han Z.D., The combustion behavior of polyacrylate ester/graphite oxide composites. Polym Adv Technol. 17 (2006) 335-340.

28. Nikiforov AA., Okhotina NA., Fayzullin IZ., Volfson SI., Rinberg R., Kroll L., In Gorkunov ES, Panin VE, Ramasubbu S, editors.AIP Conference Proceedings AIP Publishing. 1785 (2016) 030018.

29. Hong C.H., Lee Y.B., Bae J.W., Jho J.Y., Nam BU., Hwang T.W., Preparation and mechanical properties of polypropylene/clay nanocomposites for automotive parts application. J. Appl. Polym. Sci. 98 (2005) 427-433. 